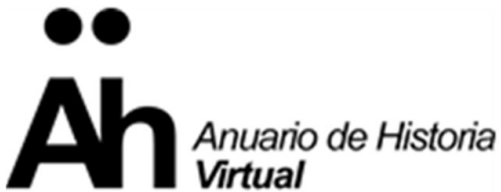

\section{Feminidad y movilidad social en las representaciones de mujeres trabajadoras. Buenos Aires (1920-1940)}

\author{
[Femininity and Social Mobility in Working Women's Representations. \\ Buenos Aires (1920-1940)]
}

\author{
Cecilia Tossounian \\ (CONICET- Universidad de San Andrés) \\ cecitoss@gmail.com
}

\begin{abstract}
Resumen
Este artículo explora cómo ha sido representada la figura de la mujer trabajadora porteña en la cultura de masas durante las décadas de 1920 y 1930. En particular, examina las ideas de feminidad y de movilidad social puestas en juego en las representaciones de empleadas de tiendas y secretarias, especialmente en el folletín y en el cine. Mientras que la historiografía ha demostrado cómo durante el peronismo las mujeres trabajadoras fueron enaltecidas por su belleza y feminidad, este artículo argumenta que este fenómeno emergió en una etapa previa y estuvo disociado de la esfera estatal. La cultura de masas retrató a la trabajadora como una joven bella que aspiraba al ascenso social mediante el matrimonio, al tiempo que se le advertía cuán poco deseable era ese camino a través del despliegue del destino trágico que aguardaba a estas jóvenes. El artículo se focaliza en estas representaciones, pero incorpora también las imágenes y voces de mujeres trabajadoras que escribieron cartas a las revistas y participaron en concursos de belleza.

Palabras claves: Feminidad - Movilidad social - Mujeres trabajadoras - Cultura de masas - Argentina
\end{abstract}

\begin{abstract}
This article explores how porteño female workers have been represented in mass culture during 1920s and 1930s. In particular, it examines ideas of femininity and social mobility put into play in representations of secretaries and saleswomen, especially in penny novels and films. While the literature on Peronism has shown how female workers were praised for their beauty and femininity, this article argues that this phenomenon emerged decades before, and was dissociated from the governmental realm. Mass culture portrayed the female worker as a beautiful, young woman who aspired to upward mobility through marriage, while at the same time it warned these women about the futility of mobility by showing the tragic destiny that awaited those young women. The article focalizes on female representations, but it also incorporates the images and voices of female workers who wrote letters to magazines and participated in beauty contests.
\end{abstract}

Keywords: Femininity - Social Mobility - Female Workers - Mass Culture - Argentina

Recibido: 12/11/2017

Evaluación: 06/02/2018

Aceptado: 26/03/2018

Anuario de la Escuela de Historia Virtual - Año 9 - N 13 - 2018: pp. 88-105.

ISSN: 1853-7049

http://revistas.unc.edu.ar/index.php/anuariohistoria 


\section{Feminidad y movilidad social en las representaciones de mujeres trabajadoras. Buenos Aires (1920-1940)}

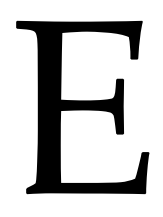

ntre octubre y noviembre de 1927, Caras y Caretas, la revista ilustrada más exitosa del momento, publicó una serie de tapas internas con retratos de varios tipos de mujeres pintados por Gregorio Lopéz Naguil, conocido pintor. Entre "La que tiene un auto", “La que juega al tennis" y "La que mira las joyerías", aparecían dos retratos de mujeres trabajadoras. En uno, titulado "La manicura", una bella joven de melena castaña, maquillaje cargado, guardapolvo blanco y zapatos de tacón era retratada de pie, junto a sus instrumentos de su trabajo. ${ }^{1}$ En el otro, "Cajera de librería", una joven de vestido negro, a la moda, uñas pintadas de rojo y zapatos, también de tacón, haciendo juego, aparecía arreglándose su rizada melena pelirroja mientras en el fondo se destacaba una estantería colmada de libros. ${ }^{2}$ Ambos retratos estaban acompañados por una poesía que describía a las jóvenes y sus quehaceres. En estas imágenes, las trabajadoras aparecían representadas como muchachas atractivas, vestidas a la última moda y sus figuras contrastaban con representaciones más usuales que las habían retratado como seres sufridos y carentes de feminidad. En las primeras décadas del siglo XX hubo un cambio significativo en la representación de la joven trabajadora. Este cambio, que se nutrió de la circulación global de discursos, imágenes y prácticas sobre la belleza, la moda y el estilo moderno, trascendió las fronteras nacionales y se expandió a nivel mundial (Freedman, Miller, Yano, 2013; Hershfield 2008; Weinbaum et al., 2008; Bontempo, 2008; Tossounian, 2013). Este artículo justamente indaga sobre las implicancias de esta transformación en términos de género y de clase en la Buenos Aires de las décadas de 1920 y 1930.

Nan Enstad (1999), en su libro sobre la influencia que la cultura del consumo tuvo en la emergencia de una feminidad específica de las mujeres trabajadoras en los Estados Unidos entre 1900 y 1940, ha argumentado que la atención de estas mujeres hacia la moda y los folletines, más que socavar, proveyó de recursos claves para la creación de su identidad como mujeres trabajadoras. Retomando su trabajo, Barbara Weinstein (2006) se ha preguntado si es posible pensar en un proceso similar para América Latina. En su estudio sobre Brasil, Weinstein ha argumentado que las ideas de feminidad y de respetabilidad se nutrieron de normas que emergían de las clases medias y que, por ese motivo, las mujeres de la clase trabajadora se disociaron cuanto pudieron del mundo del trabajo para poder así detentar una imagen femenina. Al contrario de lo observado para

\footnotetext{
1 "La manicura", Caras y Caretas, 1520, 19 noviembre 1927.

2 “Cajera de librería”, Caras y Caretas, 1517, 29 octubre 1927.
} 
90 | Feminidad y movilidad social en las representaciones de mujeres trabajadoras...

el caso brasilero, existe un consenso en la historiografía argentina en señalar cómo el peronismo enalteció la figura de la mujer trabajadora, otorgándole no solo valores morales positivos, sino también asociándola con ideales de belleza clásicos. Daniel James (2000, pp. 245-7) ha mostrado cómo el melodrama contrapuso la imagen de las mujeres trabajadoras a las mujeres de la clase alta en favor de exaltar la pureza y belleza de las primeras en contraposición a la frivolidad y perversidad sexual de las segundas. La imagen que Evita construyó de sí misma -una princesa de origen humilde, capaz de portar los más caros y ostentosos trajes y joyas, devenida luego en la austera y asexuada abanderada de los pobres-, vino a reforzar esta diferencia de clase. Las mujeres trabajadoras se identificaron con su glamour, belleza y pureza moral. De hecho, Mirta Lobato (2006) ha analizado de qué modo la elección de la reina del trabajo llevada a cabo en las festividades del $1^{\circ}$ de mayo, en donde se coronaba a la mujer trabajadora más hermosa de la Argentina, legitimó la idea de que las mujeres de la clase trabajadora podían ser bellas. Natalia Milanesio (2013, pp. 154-6) ha argumentado, por su parte, que el acceso al consumo masivo logrado por los trabajadores durante el peronismo despertó ansiedades en las clases medias y altas, quienes sintieron zozobrar la certeza sobre su pertenencia social y sus ideales de distinción y estatus al verse confrontados con la apropiación, especialmente por parte de las mujeres de sectores pobres, de lo que eran considerados sus bienes, espacios y estilos. La autora ha demostrado cómo a través de esta apropiación, que era al mismo tiempo selectiva y creativa, las mujeres de los sectores populares transformaron estos estilos en vez de solo imitarlos, reforzando, en vez de esfumarla, su identidad de clase. En otras palabras, estos estudios muestran que el peronismo posibilitó la construcción de imágenes alternativas de feminidad y respetabilidad para las mujeres trabajadoras. En este artículo, argumento que la emergencia de una feminidad específica de las mujeres trabajadoras surgió en gran medida durante un período anterior al peronismo y fue un fenómeno disociado de la esfera estatal. ${ }^{3}$ La cultura de masas y la cultura del consumo de las décadas de 1920 y 1930 contribuyeron a delinear una imagen de la mujer trabajadora caracterizada por su belleza, feminidad y por su aspiración al ascenso social, una aspiración que, sin embargo, no lograba ser concretizada y daba lugar a una reapreciación de la cultura de la clase trabajadora.

La cultura popular de este período detentó un carácter ambivalente y fluido. La historiografía ha comúnmente señalado cómo los nuevos hábitos de consumo y los mensajes culturales de la cultura de masas detentaron un carácter inclusivo y patrocinaron nociones de respetabilidad y de ascenso social (Gutiérrez, Romero, 1995, pp. 9-21; Rocchi, 1998, 2003). Más recientemente, otros estudios han demostrado que estos valores coexistieron con una visión polarizada de la sociedad, en donde ricos y pobres se encontraban permanentemente confrontados y en donde el ascenso social era criticado (Sarlo, 2000,

\footnotetext{
${ }^{3}$ En esta dirección van también los trabajos de Paula Bontempo y Graciela Queirolo. Ver específicamente Bontempo y Queirolo (2012).
} 
p. 229; James, 2000, pp. 253-60; Karush, 2012, pp. 85-7). El personaje de la joven trabajadora fue una pieza esencial de esta cultura de masas, en particular en el folletín y en el cine. Sus relatos, fuertemente marcados por el melodrama, narraron las aspiraciones a la movilidad social a través de romances entre personajes de diferentes clases sociales. Así, las bellas pobres, es decir, las muchachas jóvenes y hermosas, pero pobres muchachas que trabajaban en el centro de la ciudad y soñaban con una vida de bienestar que solo podía proveerles un hombre adinerado, se enamoraban perdidamente, pero invariablemente terminaban engañadas y abandonadas. La cultura popular argentina, así como también la de la mayoría de los países latinoamericanos, estuvo fuertemente moldeada por el melodrama, que delineó roles bastante rígidos y predictivos para las mujeres (Podalsky, 1993; López, 2004; Bergero, 2008, pp. 153-206). Ben Singer (2001, pp. 294-95) ha señalado que el melodrama expresó ciertas ansiedades modernas y, a su vez, intentó proveer simples e inmutables verdades morales que contrarrestaran esa incertidumbre. Más específicamente, el melodrama muchas veces reflejó las consecuencias sociales de la expansión de la movilidad femenina en la arena pública. ${ }^{4}$ Es un hecho que, durante este período, se dio un aumento del trabajo asalariado femenino en Buenos Aires, que pasó de un 27,9\% en 1914 a representar el 55,8\% de la población económicamente activa en 1947. A nivel nacional, en 1947 un millón doscientas mil mujeres trabajaban, 59\% de ellas en el sector terciario y $27 \%$ en el sector manufacturero (Torrado, 2003, pp. 211-15). En síntesis, el melodrama argentino diseminó una imagen de una sociedad rígidamente estratificada e inmutable, precisamente en un momento de profundos cambios sociales. Retomando estos estudios, este artículo explora productos culturales de circulación masiva para estudiar las formas en las que la figura de la joven trabajadora fue representada. Más puntualmente, examino las ideas de feminidad y de movilidad social puestas en juego en las representaciones de empleadas de tiendas y secretarias, especialmente en el folletín y en el cine de las décadas de 1920 y 1930. Argumento que, mientras, por un lado, se retrataba a las mujeres trabajadoras como muchachas atractivas, atentas al cuidado personal y conscientes de que su belleza podía permitirles soñar con un ascenso social rápido en manos de un marido pudiente, por otro lado, se advertía sobre cuán poco deseable era ese ascenso social a través del despliegue de los destinos trágicos que aguardaban a estas jóvenes. Mientras que el artículo se focaliza en estas representaciones, incorpora también, en la medida de lo posible, las voces e imágenes de las mujeres trabajadoras que escribieron cartas a las revistas pidiendo consejo sentimental y que participaron en concursos de belleza. ${ }^{5}$

\section{Mujeres bellas y trabajadoras}

La representación por excelencia de la joven trabajadora bella, coqueta y frívola, más

4 Para un estudio clásico sobre la relación entre melodrama y mujeres, ver Gledhill C. (1987).

${ }^{5}$ Para un análisis sobre los debates feministas en las discusiones sobre la cultura popular, ver Hollows J. (2000). 
atenta a su apariencia que al trabajo, arribó de la mano de comics importados de Estados Unidos. La tira cómica, originalmente titulada Tillie the Toiller, creada por Russ Westower en 1921, y varias veces reimpresa, mostraba a una joven que trabajaba como secretaria y, en su tiempo libre, como modelo. Bajo el nombre de "Pepita la dactilógrafa", "Titina", "Milonguita dactilógrafa" y su adaptación local, "Mangacha la dactilógrafa", esta joven era retratada arreglando su melena frente al espejo o eligiendo variados atuendos de moda para vestir en las diversas fiestas a las que asistía. ${ }^{6}$ Siempre atenta a su apariencia, la frivolidad y la vanidad eran sus principales características. Este estereotipo, bastante extendido, era confirmado por varios artículos de revistas que denunciaban la preocupación por la apariencia que estas jóvenes expresaban. Un artículo señalaba en tono moralizante que mientras algunas jóvenes solo se preocupaban por estar a la moda y soñaban con casarse con un hombre que las rescatara de su condición de pobreza, existían otras que estaban comprometidas con su trabajo y ayudaban a la familia con su salario. ${ }^{7}$ Los artículos que describían este nuevo fenómeno del trabajo femenino siempre resaltaban la belleza y la prolijidad en el vestir de estas jóvenes que, alegres, se dirigían a sus trabajos. ${ }^{8}$

Los folletines también recalcaban la belleza de las protagonistas de sus historias. De hecho, en el contexto de su condición humilde, la belleza de la protagonista se convertía en la precondición para el desenvolvimiento de la trama sentimental. Beatriz Sarlo (2000, p. 25) ha señalado que la belleza de la bella pobre, nombre dado a las protagonistas de las novelas semanales, era la única arma que ella tenía para desenvolverse en una sociedad que le era adversa. Esta belleza podía provenir de la sencillez de la protagonista, un argumento bastante usado por Josué Quesada, uno de los más prolíficos autores de relatos para las novelas semanales, cuando, por ejemplo, retrataba a Carmen, la protagonista de la Vendedora de Harrods, como alguien con encanto, que cuidaba su apariencia y vestía de una forma elegante y simple. En sus palabras, la protagonista era "cuidadosa con sus manos, bien peinada siempre, ofrecía el encanto atrayente de una figura gentil" y "como todas las de su clase, estaba dotada de esa gracia nativa y de esa viveza criolla." 9 Quesada dejaba entender que esta muchacha bella, honesta y amable era consciente de estar eligiendo una vida carente de romance. Otras veces, Quesada señalaba algún detalle corporal como detonante de la atención de los futuros pretendientes hacia la protagonista: las uñas pintadas o un cuerpo esbelto y armonioso se volvían clave en el relato, como sucedía en La rubia de los ojos verdes y en Melenita, respectivamente. ${ }^{10}$ Mientras que

\footnotetext{
6 "Magancha la dactilógrafa", Para Ti, 50, 24 abril 1923, p. 47. Varios números. Ver Bontempo y Queirolo (2012); Gené (2014).

${ }^{7}$ Jacqueline, “La mujer que trabaja”, Para Ti, 251, 1 marzo 1927, pp. 39, 56.

8 "El hada del teclado. Cartas de Jacqueline", Para Ti, 141, 20 enero 1925, p. 22; C. Muñoz Díaz, "La chica del centro", El Hogar, 1108, 9 enero 1931, pp. 10, 57.

9 Josué Quesada, “La Vendedora de Harrods”, en La Novela Semanal, 69, 10 marzo 1919, sin número de página.

${ }^{10}$ Josué Quesada, “La rubia de los ojos verdes", en La Novela Semanal, 142, 26 junio 1922, sin número de página; Quesada (1926, pp. 95-123). El corte de cabello remitía claramente a la estética de la joven moderna.
} 
en muchas ocasiones la belleza de las protagonistas era una característica que ellas parecían desconocer, otras veces, las menos, las bellas pobres eran conscientes de su atractivo y lo utilizaban para conquistar un "buen partido". Este era el caso de ;Qué linda era Cascabelito!, siempre de Josué Quesada, en donde la protagonista, al ser convocada por primera vez a la oficina de su jefe, quien luego se convertirá en su amante, se sintió turbada por la emoción y, a fin de adquirir, adquirir más seguridad en sí misma, dio unos toques a su peinado y arregló el delantal de trabajo, "abriendo un poco el discreto escote", mientras se dirigía a su oficina (Quesada, 1926, p. 130).

La importancia que las trabajadoras porteñas daban a la apariencia personal también aparecía descripta en un artículo escrito por la directora de la revista Para Ti, en donde se señalaba que "es tal la distinción, el aliño, la compostura" de las jóvenes que trabajan en las tiendas y oficinas del centro que "parecen pertenecer a una clase pudiente." Luego, agregaba que el truco radicaba en que las trabajadoras confeccionaban sus vestidos con telas económicas, lo que explicaba porque muchas lucían piezas y estilos a la última moda. El artículo concluía diciendo que "antes que vulgar espíritu de imitación, esa uniformidad denota el buen gusto de la mujer argentina" ${ }^{11}$ La importancia que la moda tenía en la vida de estas jóvenes es confirmada por Paula Caldo (2013), quien ha señalado el papel que jugó en la construcción de la apariencia de las maestras el tapado de piel, dado que otorgaba a sus portadoras elegancia y distinción. La posesión de ciertos artículos claramente daba estatus social a las trabajadoras y, por tanto, podría ser interpretada como una internalización de las normas sociales que emanaban de la clase alta, como argumenta Weinstein para el caso de Brasil. Sin embargo, junto a este deseo de imitación de estilos pertenecientes a una clase social superior, conviven una serie de testimonios de mujeres trabajadoras que muestra una historia un tanto diferente.

En las décadas de 1920 y 1930 se llevaron a cabo varios concursos de belleza que tenían como objetivo seleccionar a las mujeres más hermosas del país. Basados en fotografías, las revistas ilustradas que los organizaban elegían a las más bellas y publicaban los retratos de las ganadoras. Muchas de estas fotografías pertenecían a mujeres de la clase alta, por ser consideradas la máxima expresión de la belleza argentina. ${ }^{12}$ Como ha señalado Julia Ariza (2009), estos retratos de señoras y señoritas de la alta sociedad porteña, realizados por casas de fotografía profesionales como Witcomb o Van Riel, tenían un formato similar. Las retratadas lucían piezas que les otorgaban distinción -una estola de piel, un particular sombrero, joya o falda- y posaban en fotos de cuerpo entero o en primeros planos, a veces mirando a la cámara, la mayoría con la cabeza inclinada y de perfil. Debajo de sus retratos, se indicaban sus nombres y compuestos apellidos, con el fin de dar a conocer al público las bellezas destacadas y visibilizar la continuidad de los linajes que conformaban la elite porteña. A la par que se realizaba este tipo de concursos,

\footnotetext{
${ }^{11}$ Loreley, “Como he visto a la mujer argentina", Para Ti, 6 Octubre 1925, citado en Bontempo (2008, p. 98).

12 Ver por ejemplo el concurso realizado entre marzo y julio de 1925 por Caras y Caretas.
} 
94 | Feminidad y movilidad social en las representaciones de mujeres trabajadoras...

hubo también otros específicos para mujeres trabajadoras. En 1936 Caras y Caretas organizó un evento titulado "Homenaje a la belleza" en donde reporteros de la revista iban en busca de mujeres consideradas hermosas, les tomaban fotos y luego las publicaban en sus páginas. Las mujeres cuyas fotos habían sido seleccionadas y publicadas en la revista recibían además una medalla como premio. ${ }^{13}$ Aunque el objetivo era seleccionar mujeres hermosas y si bien esta definición había estado implícitamente reservada a las mujeres de la elite, los reporteros tendieron a retratar a mujeres trabajadoras en su cotidianidad. Aparecieron así publicados retratos de dos peluqueras, dos vendedoras, una empleada de farmacia y dos secretarias, una empleada de bar y una acomodadora de cine o teatro. En todas las fotos, las ganadoras aparecían retratadas en sus lugares de trabajo, generalmente usando uniforme, realizando la labor correspondiente a su oficio y mirando al objetivo de la cámara. ${ }^{14}$ Mientras en estos retratos la ocupación de las mujeres era evidenciada a través del uniforme y del tipo de trabajo que realizaban, de donde emergía con claridad que eran mujeres trabajadoras, en otras ocasiones se publicaban retratos pertenecientes a las aspirantes y ganadoras de la fiesta de la vendimia, un evento celebrado en la provincia de Mendoza en donde se elegía a la mujer más bella de los viñedos y se exaltaba a la mujer trabajadora rural. ${ }^{15}$

Es claro que en estos concursos de belleza fotográficos el tipo de profesión de la trabajadora adquiere un rol central. Antes que las obreras fabriles, invisibilizadas en las revistas de circulación masiva, fueron las mujeres que trabajaban en el sector de ventas y servicios de la ciudad de Buenos Aires las que coparon los magazines por ser consideradas atractivas y bellas. Los retratos de las ganadoras mostraban a algunas jóvenes llevando el cabello recogido y con ondas, otras maquilladas con fuertes tonos y otras con las uñas pintadas, como era la moda del momento. El uniforme, aun tapando los atuendos, dejaba intuir vestidos a la moda, acompañados de elegantes zapatos de tacón a tono. Este estilo transmitía una idea de feminidad y respetabilidad fuertemente ligada a la mujer trabajadora. Mientras que lo que denotaba su calidad de asalariada venía dado por la presencia del uniforme, la actitud corporal y el entorno laboral en donde eran sacadas las fotos. El hecho de que aparecieran fotos de trabajadoras en las revistas de circulación masiva, posando ellas tranquilas frente a la cámara, orgullosas de ser galardonas con una medalla por ser bellas y atractivas, no es un dato menor, especialmente si se compara este fenómeno con la situación de otros países latinoamericanos como Cuba, en donde la presencia de la mujer trabajadora en la cultura de masas fue mucho menor o como Brasil, en donde la categoría de mujer trabajadora carecía de valores positivos (Lotz, 2008, p. 29; Weinstein, 2006).

\footnotetext{
13 "Homenaje a la belleza", Caras y Caretas, 1960, 25 abril 1936, p. 73.

14 "Homenaje a la belleza", Caras y Caretas, 1958, 11 abril 1936, p. 81; “Homenaje a la belleza”, Caras y Caretas, 1959, 18 abril 1936, p. 73; "Homenaje a la belleza”, Caras y Caretas, 1960, 25 abril 1936, p. 73; "Mujeres bonitas", Caras y Caretas, 1964, 23 mayo 1936, p. 73; “Mujeres Bonitas”, Caras y Caretas, 1966, 6 Junio 1936, p. 75; “Mujeres Bonitas", Caras y Caretas, 1970, 4 julio 1936, p. 79.

15 “Mujeres bonitas”, Caras y Caretas, 1968, 20 junio 1936, p. 73. Ver Belej, Martin y Silveira (2005).

Anuario de la Escuela de Historia Virtual - Año 9 - Nº 13 - 2018: pp. 88-105. ISSN 1853-7049
} 
Caras y Caretas no se encontraba sola en la organización de estos concursos de fotos en donde se premiaban a jóvenes trabajadoras. Unos años antes, en 1933, el diario Noticias Gráficas había lanzado el primer concurso de belleza a nivel nacional exclusivamente para mujeres trabajadoras. ${ }^{16}$ El objetivo era seleccionar a una Miss Obrera de entre las mujeres más bellas de Buenos Aries y enviarla a España para representar a Argentina en los eventos organizados para conmemorar la proclamación de la República Española. La elección fue llevada a cabo por colegas en los lugares de trabajo, ya sea en las grandes tiendas como también en las fábricas, y las finalistas fueron entrevistadas por un jurado, que eligió a Amelia López, de diecisiete años, como la ganadora. ${ }^{17}$ Los organizadores del concurso dejaron en claro que se pretendía seleccionar a una mujer que fuera no solo bella, sino también capaz de representar a una nueva generación de mujeres trabajadoras que lograse diferenciarse de "aquellas mujeres que permanecen encerradas en sus hogares, incapaces de enfrentar la vida." Como España, según los editores y organizadores, se había convertido en una República de trabajadores en donde tanto varones como mujeres tenían los mismos derechos, era natural que la Miss Obrera argentina fuera enviada allí. ${ }^{18}$ La ganadora, de raíces españolas, había trabajado en una fábrica y en la actualidad era la asistente de un dentista. ${ }^{19} \mathrm{Al}$ ser entrevistada por los medios españoles, Amelia López admitió que, en un principio, se sorprendió de que el concurso fuera limitado a las mujeres trabajadoras, dado que, según ella, las mujeres verdaderamente bellas solo podían provenir de familias adineradas. ${ }^{20}$ Pese a su comentario, los varios retratos que se publicaron de Amelia cuando fue declarada la ganadora desafiaban esta aseveración. La imagen de esta joven de cuerpo esbelto, cabello corto y oscuro y amplia sonrisa, encajaba a la perfección con los patrones de belleza vigentes en la época y nada tenía que ver con las más clásicas representaciones de la mujer obrera, frecuentemente representada como un cuerpo enfermo o deteriorado por la fatiga del trabajo, incapaz de cobijar ningún tipo de atractivo sexual (Lobato, 2000; 2007, pp. 283-320; Armus, 2002). ${ }^{21}$ Al mismo tiempo, existía una diferencia entre las imágenes de estas jóvenes trabajadoras como Amelia López y aquellas de las mujeres de clase alta cuyos retratos aparecían en revistas como Plus Ultra o Aconcagua. En lugar de poses rígidas y demás convencionalismos fotográficos con los que se retrataba a las jóvenes de clase alta, en estas fotos las jóvenes trabajadoras posaban con evidente espontaneidad. Las caracterizaban, además, una simplicidad en el vestir -una camisa blanca con un cinturón y falda oscura- y casi ausencia de maquillaje, al menos en los

\footnotetext{
${ }^{16}$ Noticias Gráficas formaba parte, junto con el diario Crítica y El Mundo, de una nueva prensa comercial popular y masiva (Saítta, 2000).

17 "Ira a España la chica más bella”, Noticias Gráficas, 535, 26 noviembre 1932, p. 9; “La mujer más bella participará en la excursión”, Noticias Gráficas, 601, 4 febrero 1933, p. 9.

18 "Estas son las finalistas del concurso de belleza”, Noticias Gráficas, 607, 10 febrero 1933, p. 2.

19 “La Miss Obrera que irá a España”, Noticias Gráficas, 610, 13 febrero 1933, p. 5; José Venegas, “Miss Argentina desembarca mañana en Cádiz", Estampa, 272, 25 marzo 1933, pp. 17-18, p. 17.

${ }^{20}$ Venegas, “Miss Argentina desembarca mañana en Cádiz”, p. 17.

${ }^{21}$ Para patrones de belleza de la época, ver Kaczan (2013).
} 
96 | Feminidad y movilidad social en las representaciones de mujeres trabajadoras...

retratos publicados por Noticias Gráficas que, en los epígrafes de las fotos, remarcaba algunos de los rasgos plebeyos de la ganadora: sus manos toscas pero hermosas, así como su cutis desaprovechado. ${ }^{22}$ Amelia misma resaltaba su condición proletaria cuando especificaba a los reporteros españoles que era una representante de las trabajadoras: "A quien yo represento no es a la mujer argentina en general, sino a las obreras argentinas. Yo soy una obrera" declaraba, orgullosa, en La Voz de Madrid. ${ }^{23}$

En estos concursos de belleza, las participantes, ya sea mediante su apariencia, ya sea mediante sus palabras, no rehuían de su identidad trabajadora, sino más bien lo contrario. El ser trabajadoras se condecía no solo con la expresión de una cierta feminidad, sino también con la enunciación de una feminidad alternativa a la de las mujeres de clase alta, y que se expresaba en poses y vestimentas usadas de forma diferente. Y, por sobre todas las cosas, las ganadoras parecían irradiar un palpable orgullo por ser consideradas mujeres bonitas.

\section{Amor romántico y movilidad social}

Además de ser representadas en concursos, las jóvenes trabajadoras también eran los modelos de personajes de ficción, como se observa en las novelas semanales o en las películas de la época. La trama melodramática por excelencia de las mismas retomaba los temas del poema "La costurerita que dio aquel mal paso" de Evaristo Carriego. Este poema relataba la vida de la bella pobre, una joven que vivía en un barrio de Buenos Aires, trabajaba en el centro de la ciudad y se enamoraba de un joven adinerado. El personaje de la bella pobre y el tema de las implicancias morales de su viaje del barrio al centro se transformaron en un tema muy frecuentado por las novelas semanales y el cine de la época. Aun cuando esta narración melodramática presentara variaciones, las historias de amor que narraban seguían en general dos formatos. El más común culminaba en un final trágico y narraba la historia de una trabajadora que era engañada y abandonada por un varón rico y malvado, quien se aprovechaba de su inocencia. En el segundo formato, la joven trabajadora podía encontrar un cierto tipo de redención al volver al barrio, construido como un espacio tradicional en donde, a través de la dicha doméstica, los pecados de la ciudad podían ser perdonados (James, 2000, pp. 253-60).

Llamativamente, la mayoría de los finales de estas novelas sentimentales no eran felices y el mayor obstáculo a la felicidad lo constituían justamente las diferencias de clase. Margarita Pierini (2004, pp. 69-70) ha mostrado las diferencias entre la novela sentimental, de final trágico, y la novela rosa, que tenía un final feliz en donde la pareja lograba sortear los obstáculos económicos y sociales a su unión, la cual quedaba sellada con un casamiento y la promesa de una vida burguesa en donde la trabajadora pasaba a ser una futura feliz ama de casa. ${ }^{24}$ En otras palabras, mientras que las novelas

\footnotetext{
22 “La Miss Obrera que irá a España”, Noticias Gráficas, 610, 13 febrero 1933, p. 5.

${ }^{23}$ Josefina Carabias, “Miss Argentina está en Madrid”, La Voz de Madrid, 3835, 11 abril 1933, p. 3.

${ }^{24}$ Ver también Carter (1996).
} 
sentimentales retrataban una aspiración a la movilidad social ascendente por parte de la protagonista, quien soñaba con riqueza y bienestar alcanzados de una forma rápida, el final trágico de estas historias hacia recordar que, como ha señalado Beatriz Sarlo (2000, p. 135), "el amor no es más fuerte que las barreras sociales." Por tanto, el deseo de las protagonistas de las novelas semanales por alcanzar una vida burguesa, en donde pudieran dejar de ser empleadas para dedicarse al mundo doméstico gracias a la existencia del varón proveedor, se encontraba continuamente coartado, tanto por el destino trágico, manifestado por la soledad o incluso por la muerte de la protagonista, como por la propuesta de una vida proletaria en donde se podía encontrar la dicha doméstica en la simplicidad del barrio, de la familia y de un futuro compañero que perteneciera a la misma clase social que la trabajadora. En otras palabras, si bien estos relatos presentaban los encantos de una vida holgada, al mismo tiempo, denunciaban los peligros de aquella movilidad social (Karush, 2012, pp. 86-7).

En un artículo periodístico, la poetisa Alfonsina Storni señalaba la fuerte inclinación que las vendedoras y taquígrafas profesaban por los relatos de estas revistas ilustradas de carácter popular. ${ }^{25}$ Es bastante probable que este público femenino abrigara algún tipo de identificación con las historias que narraban las peripecias sentimentales de las jóvenes trabajadoras. A falta de testimonios directos, las cartas de lectores publicadas en las secciones que las revistas ilustradas reservaban para brindar consejos sentimentales permiten observar algunos elementos indicativos de la relación establecida entre el público y las temáticas propias de la cultura de masas. En estas cartas, la diferencia de clase entre novios asomaba como un tema recurrente y preocupante. Una joven comentaba estar preocupada porque su novio mostraba cierto interés en otra joven cuyos padres tenían más dinero que su familia y pedía consejo sobre cómo actuar. ${ }^{26}$ Otra lectora confesaba su amor no correspondido por un hombre de estatus social superior al de ella. Era tal su enamoramiento que estaba dispuesta a escapar de su casa para convertirse en su mucama y así poder estar juntos, lo que Leda, la consejera sentimental, califica como un plan insensato. ${ }^{27}$ Esta sección contiene incluso la misiva de un varón que escribió para pedir un consejo sentimental dado que su familia, de buena posición económica, reprobaba su unión con una muchacha de origen humilde. ${ }^{28}$ En una situación similar, pero inversa, una joven proveniente de una familia de recursos, enamorada de un joven pobre, pedía consejo ante la presión a la que la familia la sometía para que se casara con un candidato adinerado. ${ }^{29}$ En estos casos, el consejo que ambos recibieron fue que debían casarse con la joven o el joven del cual estuviesen enamorados, más allá de la respectiva situación económica. No siempre prevalecía esta

\footnotetext{
25 Tao Lao, “La perfecta dactilógrafa”, La Nación, 2º sección, 9 mayo 1920, p. 1.

${ }^{26}$ Leda, "Epistolario Sentimental", Para Ti, 144, 10 febrero 1925, p. 17.

${ }^{27}$ Leda, “Epistolario Sentimental”, Para Ti, 145, 17 febrero 1925, pp. 16, 54.

${ }^{28}$ Frank Kar Morian, “Debe casarse por amor”, Atlántida, 490, 1 septiembre 1927, p. 75.

${ }^{29}$ Fran Kar Morian, "Ama a un joven de nobles cualidades y la familia de ella quiere que se case con otro", Atlántida, 487, 11 agosto 1927, p. 75.
} 
98 | Feminidad y movilidad social en las representaciones de mujeres trabajadoras...

recomendación. A modo de ejemplo, una periodista desaconsejaba a sus lectoras trabajadoras frecuentar a varones de estatus social más alto porque, según su opinión, ellos solo pretendían aprovecharse de ellas. ${ }^{30}$ Estos dilemas románticos eran la base argumentativa de las novelas semanales y reflejaban los problemas de una sociedad socialmente heterogénea y fluida, en donde algunos miembros de la primera generación de inmigrantes adjudicaban su progreso económico y social a nociones como la respetabilidad, moralidad y esfuerzo individual (Gutiérrez y Romero, 1995; Rocchi, 1998).

De entre las tantas historias publicadas en las novelas semanales del período, la ya mencionada "La vendedora de Harrods" resalta como una de las historias más paradigmáticas sobre el personaje de la bella pobre, una obra que, por otra parte, gozó de un éxito rotundo. La atracción entre Carmen, una empleada de la tienda Harrods, en donde trabajaba para ayudar a su familia, y Juan Manuel, un joven de familia adinerada, había nacido en la gran tienda, cuando él al verla detrás del mostrador, quedó impresionado por su sencilla belleza. Gracias a su insistencia, Juan Manuel logra vencer la inicial desconfianza de Carmen y se vuelven amantes. Luego de dos años de relación, y ante la presión de la familia, Juan Manuel se casa con una "buena candidata" y abandona a Carmen. El autor, Josué Quesada, daba fin a la historia declarando que una vez más, "la sociedad triunfó sobre el amor."31 Dos meses después de este relato, y ante su éxito, Quesada publicó la secuela. Este segundo relato encuentra a Juan Manuel casado con una joven de clase alta, sin poder olvidar a Carmen; mientras esta seguía enamorada de Juan Manuel, a pesar de haber sido abandonada. Sin embargo, a pesar de ser desdichada en el amor, su carrera va en ascenso y la tienda le ofrece viajar a Europa para realizar las compras de los vestidos y accesorios de la próxima temporada. Luego de un inesperado encuentro con Juan Manuel en París, ambos organizaron un almuerzo al que Carmen se presenta vestida de forma muy elegante, dejando a Juan Manuel impresionado con su apariencia "digna de cualquier niña del gran mundo." Luego del fallecimiento de su esposa muriera en un accidente, Juan Manuel le propone casamiento a Carmen, pero ella prefirió convivir con él como su querida, sin que la ley se inmiscuyera en el amor que le profesaba. “¡Cuando el amor triunfa, Juan Manuel, la sociedad no existe!" proclamaba la protagonista al final del relato. ${ }^{32}$ Mientras que Quesada daba un final típicamente trágico a su primera historia, la secuela presentaba un final feliz que, sin embargo, no legitimaba la unión de ambos amantes ante la sociedad. En otras palabras, Carmen podía pretender pertenecer a la clase alta a través de su vestimenta, como cuando la pareja se encontraba en París, pero no se le permitía acceder de forma plena a la vida burguesa a la vida burguesa que podía depararle un matrimonio con alguien de una clase social superior. En este sentido, pese al final feliz, el mensaje era el mismo que podía leerse en muchos de los otros relatos que componían

\footnotetext{
${ }^{30}$ Gloria Alba, “Divagaciones”, Para Ti, 253, 15 marzo 1927, p. 36.

${ }^{31}$ Quesada, "La vendedora de Harrods", op. cit.

32 Josué Quesada, “Cuando el amor triunfa”, en La Novela Semanal, 79, Mayo 1919, sin número de página.

Anuario de la Escuela de Historia Virtual - Año 9 - N 13 - 2018: pp. 88-105. ISSN 1853-7049
} 
las novelas semanales y que recalcaban con insistencia lo inquebrantable de las barreras que separaban a una clase social de la otra.

En otras narraciones, la bella pobre mostraba una faceta más materialista y menos soñadora que en los relatos antes descriptos. En Melenita, de Josué Quesada, la protagonista gastaba su primer sueldo como secretaria en zapatos, medias y un sombrero, para poder ponerse a tono con la apariencia de las demás secretarias de la oficina. Pronto se olvidaba de su abuela, con quien convivía, y de su novio de la oficina, para caer en los brazos del hijo del presidente del directorio, quien la instaba a cortarse el cabello corto, arguyendo que así lo llevaban las jóvenes de la alta sociedad, y a abandonar su trabajo para transformarse en su amante. Luego de ser abandonada por él, la protagonista retornaba a la casa de la abuela, a quien pedía perdón, y se dejaba crecer dos largas trenzas que simbólicamente ponían fin a su vida anterior (Quesada, 1926, pp. 95-123). En el relato El zorro gris se llevaba al personaje materialista hasta el extremo, rompiendo incluso con las convenciones melodramáticas del personaje de la bella pobre, quien, a pesar de todo, era vista como la víctima de la situación amorosa. En este relato, el narrador se enamora de una mujer seductora, que pretendía que el hombre de sus sueños la mantuviera económicamente, le diera dinero para estar bien vestida y la llevara a pasear seguido. Como el narrador no podía seguir su ritmo de gastos, ella lo abandona, llevándose consigo toda la ropa que él le había comprado. ${ }^{33}$ El título del relato hacía referencia al tango zorro gris, que narraba la vida del cabaret, y que cantaba el personaje femenino del relato, quien se asemejaba más a las protagonistas de los tangos -las milonguitas, famosas mujeres de carácter asertivo que frecuentaban el cabaret-, que a la bella pobre (Tossounian, 2016).

En estos relatos, y con variada intensidad, las mujeres aparecían como portadoras de un intenso y a veces perjudicial deseo material, que solo podía concretizarse a través de un matrimonio exogámico que garantizara el acceso rápido a la riqueza y el bienestar. Los objetos materiales descriptos, especialmente en los relatos situados en las grandes tiendas, donde las vendedoras se encontraban rodeadas de tentaciones materiales, funcionaban como objetos de deseo para las protagonistas. ${ }^{34}$ En una escena de la película Elvira Fernández, vendedora de tiendas, una empleada encargada de la sección peletería se probaba varias veces un tapado de piel que estaba a la venta, mientras soñaba con el príncipe azul que podría proveérselo, cosa que sucedía al final de la película, cuando un joven adinerado le pedía casamiento. En otra escena, un vendedor distribuía a las empleadas medias de seda que había robado de la tienda, aduciendo que lo hacía porque el dueño era injusto con sus empleados y porque ellas debían poder llevar las mismas medias que usaban las jóvenes de clase alta. En estas descripciones de las mujeres trabajadoras, se descubría, entonces, no solo el anhelo por bienes lujosos, sino también un deseo de emulación de clase. Los relatos estaban plagados de estos personajes

\footnotetext{
${ }^{33}$ Héctor Olivera Lavié, “El zorro gris”, en La Novela Semanal, 221, 6 febrero 1922, sin número de página.

${ }^{34}$ Montaldo (2016). 
100 | Feminidad y movilidad social en las representaciones de mujeres trabajadoras...

femeninos que caían rendidos frente a los objetos que deseaban consumir. En síntesis, el guatemalteco Gómez Carrillo, en sus impresiones de Buenos Aires, describió inmutable, precisamente estas grandes tiendas como "el palacio de la tentación", en donde se notaba “el temible, el imperioso, el tiránico deseo. ¿Cómo resistir a todo lo que así atrae? Aquí (...) lo más frágil, lo más exquisito, lo más vaporoso, los encajes, las gasas, los velos, las cintas, las pieles, todo lo que constituye el adorno del icono femenino está al alcance de las manos." (Gómez Carrillo, 1921, pp. 62-3). Y concluía escribiendo que "no hay mujer (...) que resista a esta abundancia, a este lujo, a este derroche, que parece obra diabólica." (Gómez Carrillo, 1921, p. 64). A los ojos de este observador, y no tan solo de él, la tentación del consumo aparecía como un deseo difícil de controlar, al que las mujeres sucumbían pasivamente, tal como lo hacían en sus relaciones amorosas. De hecho, Adriana Bergero subrayó que incluso el lenguaje que utilizaba el autor para referirse al deseo de consumo de las mujeres se confundía con el del deseo sexual. ${ }^{35}$ Se construía así una narrativa, por lo demás bastante establecida en la cultura de masas occidental, en donde el amor por objetos y piezas suntuosas llevaba a la caída moral de las mujeres, dado que la tentación de poseer estos objetos se entrelazaba con la tentación sexual que conducía a las jóvenes a tener relaciones pre matrimoniales, como era el caso de muchos de los relatos de las novelas semanales. ${ }^{36}$ Indefectiblemente, el deseo de ascenso social que retrataban se veía constantemente amenazado por las consecuencias negativas que este deseo podía conllevar.

En el caso de las representaciones cinematográficas, al tema de la joven trabajadora que aspiraba a un futuro mejor a través de un casamiento con un hombre adinerado, las películas de Manuel Romero dieron un giro argumentativo con la aparición de jóvenes ricas que se convertían en trabajadoras. Este era el caso de dos películas escritas y dirigidas por Romero: Mujeres que trabajan (1938) y Elvira Fernández, vendedora de tiendas (1942). En ambas retrataban las vicisitudes de un grupo de mujeres que trabajaba en las grandes tiendas y sus reacciones frente a la llegada de una joven de clase alta que, por diversos motivos, se convertía en una trabajadora. En Mujeres que trabajan, el personaje de Clara encarnaba a la bella pobre, seducida y abandonada con un hijo por su jefe y Catita, rol interpretado por la actriz Niní Marshall, representaba a una joven materialista con evidentes pretensiones de ascenso social, envidiosa de la gente rica y en búsqueda de un marido que pudiera solventar sus aspiraciones materiales. La protagonista de la película, Ana María del Solar, era la joven rica cuyo padre dejaba a la familia en la bancarrota, y que pronto olvidaba su pasado de joven caprichosa y consentida para convertirse en una comprometida trabajadora, orgullosa de su nueva condición. Era tal su transformación que, cuando su novio de clase alta le propuso casamiento, ella respondió: “¿Me pides que cambie mi vida por la de antes? Ya no podría, ahora soy una mujer que trabaja.” A lo que su novio agregó: “¡Yo también seré un hombre que trabaja!”

\footnotetext{
${ }^{35}$ Para un análisis más pormenorizado de esta obra y del consumo femenino, ver Bergero (2008, pp. 153-82, especialmente p. 177). Ver también Guy $(2017,2018)$.

${ }^{36}$ Para la relación entre deseo material y caída moral, ver Valverde (1989) y Felski (1995).
} 
Elvira Fernández, vendedora de tienda presentaba un argumento similar. La protagonista, hija del dueño de la gran tienda, se hacía pasar por una trabajadora, se convertía en la líder de una huelga y se enamoraba de uno de los empleados de la tienda, con quien terminaba casándose al final de la película. En la misma escena final, su compañera de trabajo se casaba con el ex novio de Elvira, un joven de clase alta que se había enamorado de la vendedora en uno de los pocos finales felices existentes para el personaje de la bella pobre. Como era usual en las películas de Romero, la trama melodramática se expresaba a través de la confrontación entre el personaje rico y malvado y aquel generoso y pobre. Pero, en este caso, en lugar de retratar la típica historia de la bella pobre, la trama daba un giro. Las protagonistas eran jóvenes ricas y hermosas que, por diversos motivos, tenían que trabajar. Su transformación pasaba justamente a través del trabajo, una condición que cambiaba profundamente la mentalidad de estas mujeres, y de la que parecía no haber vuelta atrás. Por este motivo, estas películas pueden ser interpretadas como historias de amor interclasistas. La protagonista de origen acomodado se integraba así al mundo de las trabajadoras, cuya principal virtud era la generosidad con que aceptaban a estas desconocidas. A su vez, las trabajadoras de condición humilde, que compartían el anhelo de una vida similar a la que llevaban a las jóvenes de clase alta, descubrían, durante el devenir de la película, que aquella vida no era lo que parecía, que se trataba de frivolidad y desengaño, y que la gente buena y generosa era justamente la que se ganaba la vida con su trabajo. En estas películas, la movilidad festejada no era la ascendente, sino más bien su contrario. Era este descenso lo que les permitía a las protagonistas descubrir su propio ser, su virtud y altruismo, que hasta entonces había sido opacado por el estilo de vida de la clase alta. Estas características reforzaban la nueva identidad de clase de las protagonistas quienes, mofándose de los valores burgueses de su vida anterior, elegían transformarse también ellas en mujeres trabajadoras, generosas y altruistas. Si en estas películas había un final feliz para las bellas pobres, era porque el deseo de ascenso social, al que tanto aspiraban estas, venía reemplazado por el festejo de la vida propia de los y las trabajadores.

Ya sea en los relatos de los folletines como en las películas de Manuel Romero, el deseo de ascenso social de las protagonistas, junto a la imposibilidad de concretizarlo, se convirtió en un tema clave. En el caso de las bellas pobres de los relatos de la novela semanal, la búsqueda de la felicidad consistía en el enamoramiento y deseado casamiento con un hombre adinerado, quien, al no cumplir su promesa, ponía en evidencia los obstáculos sociales para estas uniones. La imposibilidad de que estos romances alcanzaran finales felices, entendidos como la consecución de matrimonios que convirtiesen a la trabajadora en ama de casa, señalaba tanto los límites a la movilidad de clase como la celebración de esa inmovilidad social (Sarlo, 2000, p. 229). Por su parte, en películas populares como las dirigidas por Manuel Romero, las jóvenes trabajadoras eran aclamadas sin matices. Sus deseos de ascenso social se iban esfumando con el correr del argumento, cuando se daban cuenta de la maldad y petulancia de la clase alta y de cuán afortunadas eran estas jóvenes mujeres de pertenecer a la clase trabajadora. Esto 
102 I Feminidad y movilidad social en las representaciones de mujeres trabajadoras...

venía confirmado por el deseo de descenso social de las jóvenes adineradas, que no dudaban en cambiar su vida falsa por la nobleza del mundo trabajador.

\section{A modo de conclusión}

Las representaciones de las jóvenes trabajadoras, especialmente de aquellas que trabajaban en el sector servicios de la ciudad de Buenos Aires, estaban profundamente atravesadas por construcciones de género y clase. Por una parte, los retratos de estas jóvenes expresaban feminidad y respetabilidad. Los vestidos sueltos que llegaban a la rodilla, la melena, el maquillaje cargado y, en general, el deseo de objetos que les eran momentáneamente inaccesibles, como vestimentas elegantes, estolas de piel, joyas o medias de seda, hablaban de un gusto particular, muy cercano al estilo de las mujeres de la clase alta. Sin embargo, estas imágenes, más que reflejar los valores de género de aquella clase, tendieron a reforzar la identidad trabajadora de estas jóvenes. Los retratos de mujeres bellas y trabajadoras publicados en la revista Caras y Caretas mostraban a estas jóvenes posando con sus uniformes, en sus lugares de trabajo, sonriendo a la cámara, orgullosas de haber sido seleccionadas por su belleza. Amelia López, elegida Miss Obrera, encarnaba un particular tipo de belleza, estilo y comportamiento, que provenía de su condición trabajadora. Los organizadores del concurso de hecho reafirmaron esta diferencia mostrando los efectos del trabajo sobre la piel de esta joven. Pero incluso ella misma retenía con orgullo el ser diferente de las mujeres de clase pudiente, pues, siendo una trabajadora, se consideraba de una belleza inferior.

Por otra parte, las historias de amor interclasistas que narraban las novelas semanales y las películas loaban la condición trabajadora de las protagonistas, pero eran relatos que no dejaban de mostrar un cariz ejemplificante y admonitorio, advirtiendo los peligros inherentes al ascenso social. Las jóvenes trabajadoras, en estas obras, debían contener su pasión o ambición desmesurada, dado que era más meritorio pertenecer a la clase trabajadora que pretender ser alguien que no se era. Es por esto que estas jóvenes pocas veces se disociaban del mundo del trabajo para pasar a formar parte del ideario burgués conformado por mujeres amas de casa mantenidas económicamente por sus maridos. Esta posibilidad era casi nula según el rígido formato del melodrama, que retenía a estas jóvenes víctimas de una fatalidad incontrolable. Incluso, cuando el típico relato de la bella pobre daba un giro original y retrataba romances interclasistas en donde las adineradas eran las mujeres, como sucedía con las películas de Manuel Romero, las protagonistas terminaban uniéndose al mundo popular, dejando atrás su pasado de niñas bien y abrazando la identidad de las mujeres de clase trabajadora.

En suma, en la Buenos Aires de las décadas del 1920 y 1930, las mujeres trabajadoras enarbolaron nociones de feminidad, respetabilidad y ascenso social que circulaban en la cultura del consumo y la cultura de masas del período, sin por eso disociarse del mundo del trabajo. Más que signos de la emergencia de una típica identidad de clase media, estas nociones emanaban de una cultura de masas que contenía valores y mensajes 
contrastantes. Diez años después este escenario mutará con la llegada del peronismo. Entonces, ocurrirá que la clase media afianzará su identidad a través de la defensa de una serie de valores que sentía que estaban en peligro ante el acceso al consumo masivo por parte de las clases populares y especialmente por parte de las mujeres trabajadoras, ahora públicamente homenajeadas. Sin embargo, estas mismas mujeres trabajadoras ya habían detentado una identidad que conjugaba de forma armónica nociones de feminidad con valores de la clase trabajadora mucho antes de la llegada de Juan Domingo y Eva Perón al poder.

\section{Referencias bibliográficas:}

Armus, D. (2002). Milonguitas en Buenos Aires (1910-1940): tango, ascenso social y tuberculosis. Manguinhos, 9, 187-207.

Ariza, J. (2009). Bellezas argentinas y femmes de lettres: representaciones de la mujer en la revista ilustrada Plus Ultra (1916-1930). En L. Malosetti y M. Gené (Comps.), Impresiones Porteñas: Imagen y palabra en la historia cultural de Buenos Aires (pp. 81106). Buenos Aires: Edhasa.

Belej, C., Martin, A.L., y Silveira, A. (2006). La más bella de los viñedos. Trabajo y producción en los festejos mendocinos (1936-1955). En M. Lobato (Ed.), Cuando las mujeres reinaban (pp. 45-76). Buenos Aires: Biblos.

Bergero, A. (2008). Intersecting Tango: Cultural Geographies of Buenos Aires, 1900-1930. Pittsburgh: University of Pittsburgh Press.

Bontempo, P. y Queirolo, G. (2012). Las "chicas modernas" se emplean como dactilógrafas: feminidad, moda y trabajo en Buenos Aires (1920-1930). Bicentenario. Revista de Historia de Chile y América, 11 (2), 51-76.

Bontempo, P. (2008). Para Ti: El cuerpo de la mujer moderna (1922-1928) (Tesis de maestría). Universidad de San Andrés, Buenos Aires, mimeo.

Caldo, P. (2013). El "hábito" hace a la maestra. Hacia una historia de las prácticas de consumo de las mujeres dedicadas a la docencia en Argentina, 1939-1943. Naveg@mérica. Revista electrónica de la Asociación Española de Americanistas. (15/10/2017).

Carter, E. (1996). Deviant Pleasures? Women, Melodrama, and Consumer Nationalism in West Germany. En V. De Grazia y E. Furlough (Eds.), The Sex of Things. Gender and Consumption in Historical Perspective (pp. 359-79). Berkeley: University of California Press.

Enstad, N. (1999). Ladies of Labor, Girls of Adventure: Working Women, Popular Culture, and Labor Politics at the Turn of the Twentieth Century. New York: Columbia University Press.

Felski, R. (1995). The Gender of Modernity. Cambridge (Ma.): Harvard University Press. 
104 | Feminidad y movilidad social en las representaciones de mujeres trabajadoras...

Freedman, A., Miller, L., y Yano, C. (Eds.) (2013). Modern Girls on the Go. Gender, Mobility and Labor in Japan. Standford: Standford University Press.

Gené, M. (2014). De la flapper norteamericana a la morocha argentina o de cómo el humor elabora modelos de belleza. Ponencia presentada en AHILA, Berlín.

Gledhill, C. (1987). The Melodramatic Field: An Investigation. En E. Gledhill (Ed.), Home is Where the Heart Is: Studies in Melodrama and Women's Film (pp. 5-38). London: British Film Institute.

Gutiérrez, L. y Romero, L. A. (1995). Introducción. En L. Gutiérrez y L. A. Romero (Eds.), Sectores populares, cultura y política: Buenos Aires en la entreguerra (pp. 9-21). Buenos Aires: Sudamericana.

Guy, D. (2016). Comprar, comer y socializar en la calle Florida entre 1914 y 1920. En S. Hallstead y R. Root (Comps.), Pasado de moda. Expresiones culturales y consumo en la Argentina (pp. 138-52). Buenos Aires: Ampersand.

Guy, D. (2018). Producción, ventas y consumo: reflexiones sobre el papel del género en las tiendas grandes de Buenos Aires, 1883-1930. Descentrada, 2 (1), 1-16.

Hershfield, J. (2008). Imagining la Chica Moderna: Women, Nation and Visual Culture in Mexico 1917-1936. Durham: Duke University Press.

Hollows, J. (2000). Feminism, femininity and popular culture. Manchester: Manchester University Press.

James, D. (2000). Doña María's Story: Life History, Memory and Political Identity. Durham: Duke University Press.

Kaczan, G. (2013). Salud, belleza, aire libre. Montaje de la apariencia femenina a orillas del mar (circa 1920-1940). Arenal, 20(1), 129-57.

Karush, M. (2012). Culture of Class. Radio and Cinema in the Making of a Divided Argentina. Durham and London: Duke University Press.

Lobato, M. (2000). Lenguaje laboral y de género en el trabajo industrial: primera mitad del siglo XX. En F. Gil Lozano, V. Pita y G. Ini (Comps.), Historia de las mujeres en la Argentina (pp. 95-115). Buenos Aires: Taurus.

Lobato, M., Damilakou, M. y Tornay, L. (2005). Las Reinas del Trabajo bajo el Peronismo. En M. Lobato (Ed.), Cuando las mujeres reinaban. Belleza, virtud y poder en la Argentina en el siglo XX (pp. 77-120). Buenos Aires: Biblos.

Lobato, M. (2007). Historia de las trabajadoras en la Argentina (1869-1960). Buenos Aires: Edhasa.

López A. M. (2004). Tears and Desire: Women and Melodrama in the "Old" Mexican Cinema. En A. Del Sarto, A. Ríos y A. Trigo (Eds.), The Latin American Cultural Studies Reader (pp. 441-58). Durham-London: Duke University Press.

Lotz, L. (2008). Leading the Life of a Modern Girl: Representations of Womanhood in Cuban Popular Culture 1919-1929 (Tesis doctoral). Chapel Hill: University of North Carolina, mimeo.

Montaldo, G. (2016). Museo del consumo: archivos de la cultura de masas en la Argentina. Buenos Aires: Fondo de Cultura Económica. 
Milanesio, N. (2013). Workers Go Shopping in Argentina: The Rise of Popular Consumer Culture. Albuquerque: University of New Mexico Press.

Pierini, M. (Coord.) (2004). La Novela Semanal. Buenos Aires 1917-1927. Un proyecto editorial para la ciudad moderna. Madrid: CSIC.

Podalsky, L. (1993). Disjointed Frames: Melodrama, Nationalism and Representation in 1940s' Mexico. Studies in Latin American Popular Culture, 12, 57-73.

Quesada J. (1926). Almas de mujeres. Buenos Aires: H.A. Tommasi. Controlar la referencia Rocchi, F. (1998). Consumir es un placer: la industria y la expansión de la demanda en Buenos Aires a la vuelta del siglo pasado. Desarrollo Económico, 148, 533-58.

Rocchi, F. (2003). La Americanización del Consumo: Las Batallas por el Mercado Argentino (1920-1945). En M. Barbero y A. Regalsky (Comps.), Americanización: Estados Unidos y América Latina en el siglo XX (pp. 131-89). Buenos Aires: EDUNTREF.

Saítta, S. (2000). El periodismo popular en los años veinte. En R. Falcón (Comp.), Nueva Historia Argentina, Tomo VI, (pp. 437-71). Buenos Aires: Sudamericana.

Sarlo, B. (2000). El Imperio de los Sentimientos. Narraciones de circulación periódica en Argentina (1917-1927). Buenos Aires: Norma.

Singer, B. (2001). Melodrama and Modernity: Early Sensational Cinema and Its Contexts. New York: Columbia University Press.

Torrado, S. (2003). Historia de la familia en la Argentina moderna 1870-2000. Buenos Aires: De la Flor.

Tossounian, C. (2013). Images of the Modern Girl: From the Flapper to the Joven Moderna (Buenos Aires 1920-1940). Forum for Inter-American Research, 6 (2), 41-70.

Tossounian, C. (2016). Milonguitas: Tangos, Gender and Consumption in Buenos Aires 1920-1940. E.I.A.L., 27 (2), 29-45.

Valverde, M. (1995). The Love of Finery: Fashion and the Fallen Woman in NineteenthCentury Social Discourse. Victorian Studies, 32 (2), 168-88.

Weinbaum A., et al. (2008). The Modern Girl around the World. Consumption, Modernity and Globalization. Durham: Duke University Press.

Weinstein, B. (2006). “They don't even look like women workers": Femininity and Class in Twentieth-Century Latin America. International Labor and Working-Class History, 69, 161-76.

Para citar este artículo:

Tossounian, Cecilia (2018). Feminidad y movilidad social en las representaciones de mujeres trabajadoras. Buenos Aires (1920-1940). Anuario de la Escuela de Historia Virtual, 13, 88-105. 